\title{
The supraclavicular artery island flap (SCAIF) in head and neck reconstruction: an Italian multi-institutional experience
}

\author{
II lembo peduncolato sovraclaveare (SCAIF) nella ricostruzione del distretto testa-collo: \\ esperienza multicentrica italiana
}

\author{
L. GIORDANO ${ }^{1}$, D. DI SANTO ${ }^{1}$, S. BONDI ${ }^{1}$, F. MARCHI ${ }^{2}$, A. OCCHINI ${ }^{3}$, G. BERTINO ${ }^{3}$, A. GRAMMATICA ${ }^{4}$,

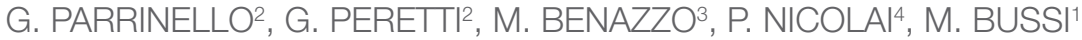 \\ ${ }^{1}$ Otolaryngology Service, Head and Neck Department, San Raffaele Hospital, Vita-Salute University, Milan, Italy; \\ 2 Department of Otorhinolaryngology-Head and Neck Surgery, Ospedale Policlinico San Martino, \\ University of Genoa, Italy; ${ }^{3}$ Department of Otorhinolaryngology, IRCCS Policlinico San Matteo Foundation, \\ University of Pavia, Italy; ${ }^{4}$ Unit of Otorhinolaryngology-Head and Neck Surgery, Department of Surgical Specialties, \\ Radiological Sciences and Public Health, University of Brescia, Italy
}

\section{SUMMARY}

The supraclavicular artery island flap (SCAIF) is a thin and pliable pedicled flap that is easy and quick to harvest. Thanks to its particular features and high reliability, it is best indicated for the elderly or most fragile patients. SCAIF is very versatile, as it can be used for reconstruction of oral cavity, oropharynx, hypopharynx, facial and cervical skin and tracheostomal defects. We began using this flap in four Italian tertiary referral centres, with several indications, both as first treatment and as salvage surgery. The aim of the study was to demonstrate the easy reproducibility of the flap among four different centres. A series of 28 patients underwent head and neck reconstructions with SCAIF with no recorded complications during flap harvesting. After the very first cases, harvesting time was approximately 45 minutes; 24 patients had successful flap integration at the recipient site, while the remaining 4 suffered from partial flap necrosis, two of whom needed revision surgery. Other minor complications were reported at the recipient site, always at the most distal and most delicate portion of the flap. Donor site was always closed primarily, with only three cases of partial suture dehiscence. We only selected the most fragile patients for SCAIF reconstruction, such as the elderly or those with one or more comorbidities; for this reason, we reported some serious systemic complications and one intraoperative death. SCAIF is an easy reproducible flap, with multiple possible indications. Its use as an alternative to free flaps in the head and neck region is nowadays under discussion. Its use should be encouraged among head and neck surgeons thanks to its various advantages.

KEY WORDS: Supraclavicular flap $\bullet$ Head and neck reconstruction $\bullet$ Pedicled flap $\bullet$ Fragile patients

\section{RIASSUNTO}

Il lembo peduncolato sovraclaveare è un lembo sottile e malleabile, facile e veloce da scolpire. Grazie alle sue peculiari caratteristiche e alla sua alta affidabilità trova un'ottima possibilità di utilizzo nei pazienti più anziani o più compromessi. Si tratta di un lembo molto versatile, che può essere utilizzato per ricostruzioni del cavo orale, dell'orofaringe, dell'ipofaringe, della cute della regione della faccia e del collo e dei difetti del tracheostoma. Abbiamo iniziato ad utilizzare il lembo sovraclaveare in quattro centri italiani di riferimento, con diverse indicazioni, sia come prima scelta ricostruttiva, sia come terapia di salvataggio. Con il presente studio ci si propone di dimostrare la agevole riproducibilità del lembo nei quattro diversi centri. 28 pazienti sono stati trattati con ricostruzione del distretto testa-collo mediante lembo peduncolato sovraclaveare, senza evidenza di complicanze durante l'allestimento del lembo. Dopo i primissimi casi, il tempo di allestimento si è stabilizzato attorno ai 45 minuti. In 24 casi si è verificata un'ottima integrazione del lembo nel sito ricevente, mentre i restanti 4 pazienti hanno sofferto una parziale necrosi del lembo, e 2 di essi hanno necessitato di una revisione chirurgica. Altre complicanze minori sono state riscontrate a carico del sito ricevente, sempre a livello della porzione distale e più delicata del lembo. Il sito donatore è sempre stato chiuso mediante sutura diretta, con solo tre casi di parziale deiscenza della ferita. Sono stati selezionati per ricostruzione mediante lembo peduncolato sovraclaveare solo i pazienti più delicati, ovvero i più anziani o coloro che soffrivano di una o più comorbidità; per questo motivo abbiamo riportato alcune complicanze sistemiche severe e persino un caso di morte intraoperatoria. Il lembo peduncolato sovraclaveare è un lembo riproducibile, con multiple possibili indicazioni. Nonostante il suo utilizzo in alternativa ai lembi liberi nelle ricostruzioni del distretto testa-collo rimanga dibattuto, il lembo peduncolato sovraclaveare dispone di numerosi vantaggi e pertanto il suo impiego andrebbe incoraggiato tra i chirurghi che si occupano di chirurgia ricostruttiva.

PAROLE CHIAVE: Lembo sovraclaveare $\bullet$ Ricostruzione testa-collo $\bullet$ Lembo peduncolato $\bullet$ Pazienti delicati

Cite this article as: Acta Otorhinolaryngol Ital 2018;38:497-503. https://doi.org/10.14639/0392-100X-1794

(C) Società Italiana di Otorinolaringoiatria e Chirurgia Cervico-Facciale 


\section{Introduction}

The supraclavicular artery island flap (SCAIF) is a fasciocutaneous pedicled flap that is gaining an increased popularity over recent years, thanks to its high versatility, and has been proposed for reconstruction of many head and neck defects. The SCAIF is harvested from the supraclavicular and deltoid region and can be transferred to the head and neck region, thanks to an arc of rotation ranging up to $180^{\circ}$. This flap is a precious option for skin reconstruction due to similar colour and texture to the nearby skin, but at the same time it is useful for reconstructing all the defects of head and neck regions, because it can be de-epithelialised and tunnelled into the neck.

The flap is hairless, thin and pliable, and has been proposed as a valid alternative to free flaps ${ }^{1}$, especially to the radial forearm free flap (RFFF). In fact, SCAIF is easy and quick to harvest, and as it is pedicled it does not require a dedicated team for microsutures. It has been proposed as a first choice flap for patients who would benefit from shorter and simpler procedures because of comorbidities ${ }^{2}$.

The flap is known since the beginning of the 19th century, but was abandoned because of the high number of complications, probably caused by the scarce knowledge of the vascular anatomy of the shoulder. In the 1990s, Pallua ${ }^{34}$ recovered this flap for facial and cervical skin reconstruction after burn injuries, and subsequently in 2009 Chiu $^{5}$ first used it for head and neck reconstruction after oncologic surgery. Since then, multiple reports about SCAIF appeared in the literature ${ }^{6-10}$, and in a recent review it was proposed as a possible reconstructive option for the floor-of-mouth and hypopharynx ${ }^{11}$.

The flap is based on the supraclavicular artery, a branch of the transverse cervical artery; the vessel diameter generally ranges between 1.1 and $1.5 \mathrm{~mm}$. The venous drainage originates from venae comitantes running together with the artery and reaches the transverse cervical vein or the external jugular vein ${ }^{45}$. A major cutaneous nerve from the cervical plexus is found in most cases, located $1-2 \mathrm{~cm}$ anterior to the pedicle toward the clavicle ${ }^{12}$.

The Italian experience in SCAIF application is limited, but recently consensus is increasing ${ }^{213}$.

Popularity of the SCAIF use may be encouraged by its easy and quick harvesting and by its multiple possible applications. In this paper, we present the experience with SCAIF reconstruction from four Italian Head and Neck Surgery Departments. The present study aims at evaluating the reproducibility of the flap, and underlining indications, outcomes and complications, in order to increase awareness about the advantage of SCAIF as an alternative to free flaps for moderate to large defects of the head and neck region.

\section{Materials and methods}

Since October 2012 to April 2017, a series of 28 patients (53-95 years old, 16 males and 12 females) underwent reconstructions with SCAIF in 4 Italian tertiary referral hospitals ("San Raffaele" Hospital in Milan, "Policlinico San Matteo" in Pavia, "Ospedale Policlinico San Martino" in Genoa and University Hospital of Brescia). Table I shows demographic data.

All the patients were affected by locally advanced head and neck malignancies, recurrent cancers or failure of previous reconstruction, except a case of a pT1 hypopharyngeal retrocricoid carcinoma in a patient who was previously irradiated for a tongue base lymphoma.

As a general rule, the use of SCAIF as a first choice flap for head and neck reconstructions was preferred for older patients or for those with the most serious comorbidities. All of our patients were affected by one or more comorbidities. Most suffered from cardiovascular or metabolic comorbidities, and $43 \%$ of them were affected by multiple comorbidities.

The supraclavicular artery arises from the transverse cervical artery. It is mandatory to demonstrate the presence of the artery and to locate it preoperatively. If the patient previously underwent a neck dissection, an angio-CT scan was preferred to demonstrate the artery. Otherwise, the artery was located and marked with a pencil Doppler probe. When used for hypopharyngeal reconstruction, the supraclavicular artery was searched bilaterally, and the most convincing side was chosen, to maximise the chances of flap survival.

All four centres follow the flap harvesting technique described by Kokot ${ }^{10}$. The pedicle is found in a triangular region between the posterior edge of the sternocleidomastoid muscle, the external jugular vein and the clavicle. Size of the flap was designed according to the distance of the site of reconstruction and extension of the defect. Flap rising was conducted from distal to proximal, dissecting it in a subfascial plane. The pencil Doppler probe may help to locate the artery intraoperatively. The flap is dissected until its most proximal portion, where the supraclavicular artery arises from the transverse cervical artery; in this region, the pedicle is surrounded by fascia and connective tissues: it can be demonstrated with a Doppler probe, and can be dissected without the need to expose the supraclavicular artery. At the same time, no particular effort was made to locate and preserve the nervous pedicle of the flap.

After harvesting was completed (Fig. 1), the flap was rotated to reach the site of reconstruction and, in most cases, the intermediate portion of the flap was de-epithelialised 


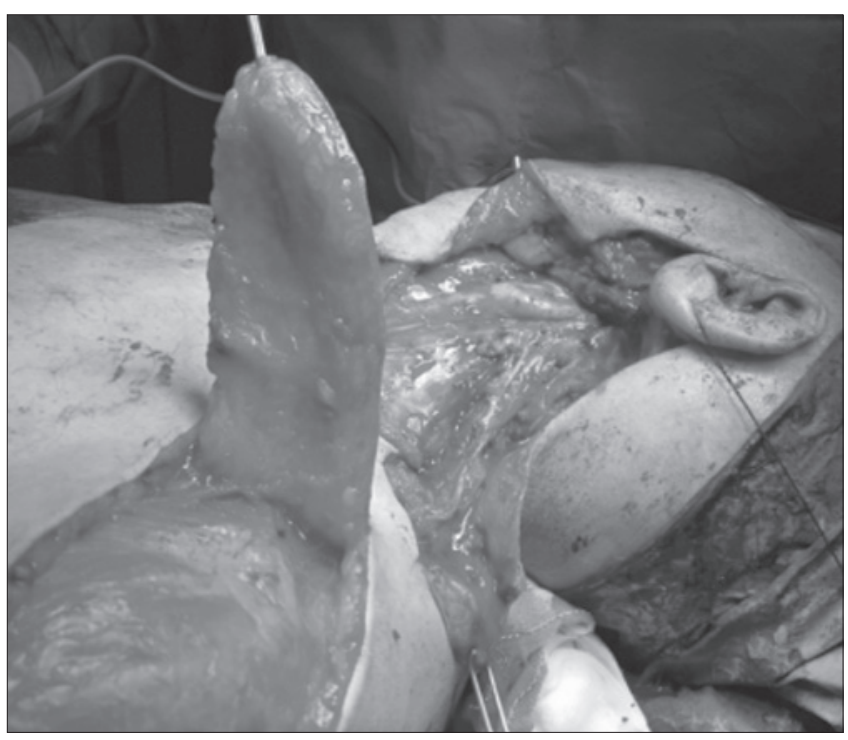

Fig. 1. SCAIF harvesting. The flap will be tunnelled and used for cervical skin reconstruction, with a $180^{\circ}$ arc of rotation.

and the flap was tunnelled under the cervical skin. For facial and cervical skin reconstruction, the flap can be tunnelled or simply rotated to cover the defect (these latter cases are marked with an "*” in Table I). After simple rotation of the flap, the pedicle can be cut after at least 3 weeks to gain better aesthetic and functional outcomes.

\section{Results}

In Table II patient distribution between centres, indications and complications are shown. No intraoperative complications during flap harvesting were reported in any of the four institutions and none of our patients needed a postoperative ICU stay.

Harvesting time decreased from 55-60 minutes in the first cases to approximately 40-45 minutes in the latter ones.

24 of $28(86 \%)$ patients had successful integration of the flap into the recipient site with closure of the defect (Fig. 2). The donor site was always sutured directly, avoiding a skin graft. Most of patients referred a sensation of great tension to the donor shoulder, which always disappeared within a few months.

When used for facial and cervical skin reconstruction, colour and texture of the flap were always very similar to those of the recipient site (Fig. 3).

Recipient site complications were always caused by desquamation or loss of the most distal portion of the flap. We reported one case of distal tip desquamation, which was managed with conservative treatment and healing by secondary intention. Partial flap loss occurred in 4 cases. It was treated conservatively in two cases, in which the SCAIF was used for cutaneous reconstructions. Revision surgery was needed for two patients who developed a pharyngocutaneous fistula, one after lateral oropharyngeal wall reconstruction and the other after revision surgery for a previous fistula after total pharyngolaryngectomy. None of the partial flap necrosis occurred to the 4 previously irradiated patients.

Considering the donor site, we observed three cases of dehiscence of the suture, which were all treated conservatively.

Table I. Patient demographics.

\begin{tabular}{|c|c|}
\hline $\begin{array}{l}\text { Mean age } \\
\text { at surgery }\end{array}$ & 72.6 years (range $53-95)$ \\
\hline Sex & $\begin{array}{l}16 \text { Male } \\
12 \text { Female }\end{array}$ \\
\hline \multirow[t]{5}{*}{$\begin{array}{l}\text { Site } \\
\text { of the lesion }\end{array}$} & $\begin{array}{l}\text { Oral cavity } \\
\text { 3 SCC: } \\
\text { - } 1 \text { pT2 pN2b - stage IVA } \\
\text { - } 2 \text { pT4a pNO - stage IV A }\end{array}$ \\
\hline & $\begin{array}{l}\text { Oropharynx } \\
\text { 1 SCC: pT4a pN1 - stage IV A } \\
\text { 1 AdCC: pT4a pNO - stage IV A }\end{array}$ \\
\hline & $\begin{array}{l}\text { Hypopharynx } \\
7 \text { SCC: } \\
\text { - } 1 \text { pT1 pNO - stage I } \\
\text { - } 2 \text { pT4a pNO - stage IV A } \\
\text { - } 1 \text { pT4a pN1 - stage IV A } \\
\text { - } 1 \text { pT4a pN2a - stage IV A } \\
\text { - } 1 \text { pT4a pN2b - stage IV A } \\
\text { - } 1 \text { pT4a pN2c - stage IV A } \\
5 \text { Revision surgeries for pharyngocutaneous fistula }\end{array}$ \\
\hline & $\begin{array}{l}\text { Facial skin } \\
1 \text { Parotid Undifferentiated Carcinoma: pT4b pN2b - stage IV B * } \\
5 \text { Parotid SCC Metastases }\left(1^{*}\right)\end{array}$ \\
\hline & $\begin{array}{l}\text { Cervical skin } \\
3 \text { SCC Metastases with skin invasion } \\
2 \text { SCC: } \\
\text { - } 1 \text { pT3 pNO - stage III * } \\
\text { - } 1 \text { pT3 pN2b - stage IV * }\end{array}$ \\
\hline $\begin{array}{l}\text { Previous } \\
\text { treatments }\end{array}$ & $\begin{array}{l}3 \mathrm{RT} \\
1 \mathrm{CRT}\end{array}$ \\
\hline \multirow[t]{8}{*}{ Comorbidities } & $\begin{array}{l}18 \text { (64\%) Cardiovascular - } 12 \text { HBP, } 6 \text { CAD, } \\
6 \text { arrhythmia (2 AF), } 3 \text { PAD, } 1 \text { CHF, } 1 \text { Ml }\end{array}$ \\
\hline & 8 (29\%) Metabolic - 7 Obesity, 2 Type 2 Diabetes \\
\hline & 4 (14\%) Pulmonary - 4 COPD \\
\hline & 4 (14\%) Neurologic - 2 stroke, 1 TIA, 1 Parkinson Disease \\
\hline & 4 (14\%) Hepatic - 3 Chronic Hepatitis, 1 HCC \\
\hline & 2 (7\%) Psychiatric - 2 MDD \\
\hline & $1(4 \%)$ Autoimmune - SLE \\
\hline & $12(43 \%)$ Multiple \\
\hline
\end{tabular}

SCC: Squamous Cell Carcinoma; AdCC: Adenoid Cystic Carcinoma; HBP: High Blood Pressure; CAD: Coronary Artery Disease; AF: Atrial Fibrillation; PAD: Peripheral Artery Disease; CHF: Congestive Heart Failure; MI: Mitral Insufficiency; COPD: Chronic Obstructive Pulmonary Disease; TIA: Transient Ischaemic Attack; HCC: Hepatocellular Carcinoma; MDD: Major Depressive Disorder; SLE: Systemic Lupus Erythematous;

*: cases in which the flap was simply rotated without tunnelling under cervical skin. 
Table II. Patient distribution between centres, indications and complications.

\begin{tabular}{lcc} 
& Indications & Complications \\
Ospedale & 4 CCR & 2 PFN \\
San Raffaele & 3 FCR & 2 SSD \\
Milan & 3 HPR & 1 pulmonary embolism \\
& 2 OCR & 1 peripheral artery thrombosis \\
& 2 OPR & 1 intraoperative death \\
Policlinico & $1 \mathrm{HPR}$ & 1 PFN \\
San Matteo & $1 \mathrm{CCR}$ & \\
Pavia & $3 \mathrm{R}-\mathrm{HPR}$ & $1 \mathrm{PFN}$ \\
Ospedale & $3 \mathrm{HPR}$ & $1 \mathrm{SSD}$ \\
Policlinico San Martino & $2 \mathrm{R}-\mathrm{HPR}$ & 1 respiratory acidosis \\
Genoa & $1 \mathrm{FCR}$ & 1 sepsis \\
University Hospital & $2 \mathrm{FCR}$ & \\
Brescia & $1 \mathrm{OCR}$ & \\
\hline
\end{tabular}

CCR: Cervical Cutaneous Reconstruction; FCR: Facial Cutaneous Reconstruction; OCR: Oral Cavity Reconstruction; OPR: Oropharyngeal Reconstruction; HPR: Hypopharyngeal Reconstruction; R-HPR: Revision surgery after previous Hypopharyngeal Reconstruction; PFN: Partial Flap Necrosis (< 50\%); SSD: Shoulder Suture Dehiscence.

As we propose this flap preferentially for the elderly or for most fragile patients, we also report systemic complications. There was one case of intraoperative death at the end of a surgery for a lymph node metastasis with massive skin invasion from SCC of the helix. During SCAIF suturing the patient had a massive myocardial infarction and cardiac arrest. 4 of $28(14 \%)$ patients reported serious postoperative systemic complications that were not related to the procedure itself, but to their general compromised conditions. Reported complications were sepsis, respiratory acidosis, pulmonary embolism and arterial thrombosis, but none of the patients died because of these complications.

Postoperative hospital stay was related to the site of reconstruction and presence of complications, being shorter after cutaneous reconstructions (5-15 days), and longer after oral cavity, oropharyngeal, or hypopharyngeal reconstructions (9-45 days).

SCAIF was used 11 times to cover a skin defect in the face or in the neck, and always demonstrated colour and texture that perfectly matched the site of reconstruction. Among these, the flap was simply rotated without tunnelling in 4 cases. In 2 patients, the pedicle was subsequently cut after at least 3 weeks; the remaining 2 patients refused cutting of the pedicle to maintain sensation on the skin flap.

Three patients (11\%) reported some kind of sensation of the flap, which was referred as skin sensation after cutaneous reconstruction or wet sensation to the shoulder when drinking after hypopharyngeal reconstruction.

\section{Discussion}

The results of our initial experience with the SCAIF are similar to those reported in the literature ${ }^{5-10}$. This flap, although in our initial experience, was found to be safe and reliable in all four centres, with reproducible results. The application of SCAIF in head and neck reconstructive surgery may offer a series of advantages. First, flap harvesting is easy and quick, and does not require microsurgical expertise. Vascular microsutures needed during free tissue transfer are time-consuming and expose the patient to eventual thrombotic complications of the anastomoses. In our experience, SCAIF harvesting time was quickly reduced after the very first cases, to approximately 45 minutes. Comparable harvesting times are reported in the literature ${ }^{81415}$. The learning curve was very quick in all four centres, and no surgeon reported any difficulty in flap harvesting. Thanks to its reduced harvesting time, it is best indicated for the most fragile patients ${ }^{2}$, who would benefit from simpler and shorter procedures.
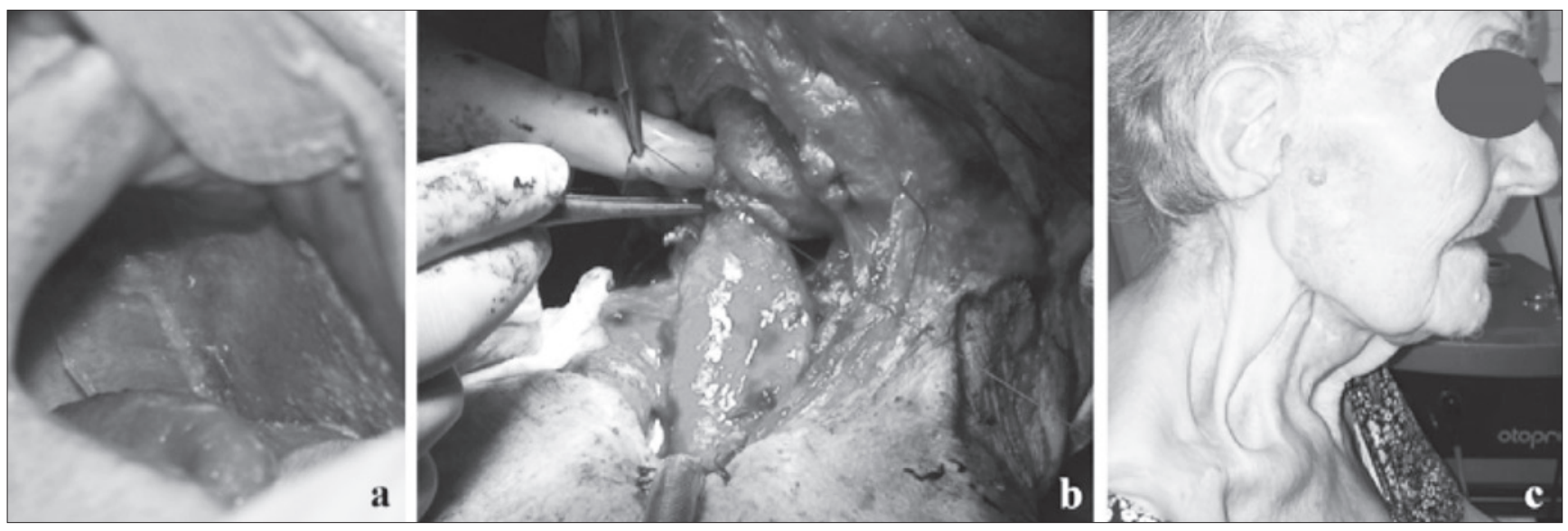

Fig. 2. Different indications to SCAIF reconstruction: oral cavity (a), hypopharynx (b) and cervical skin (c). 

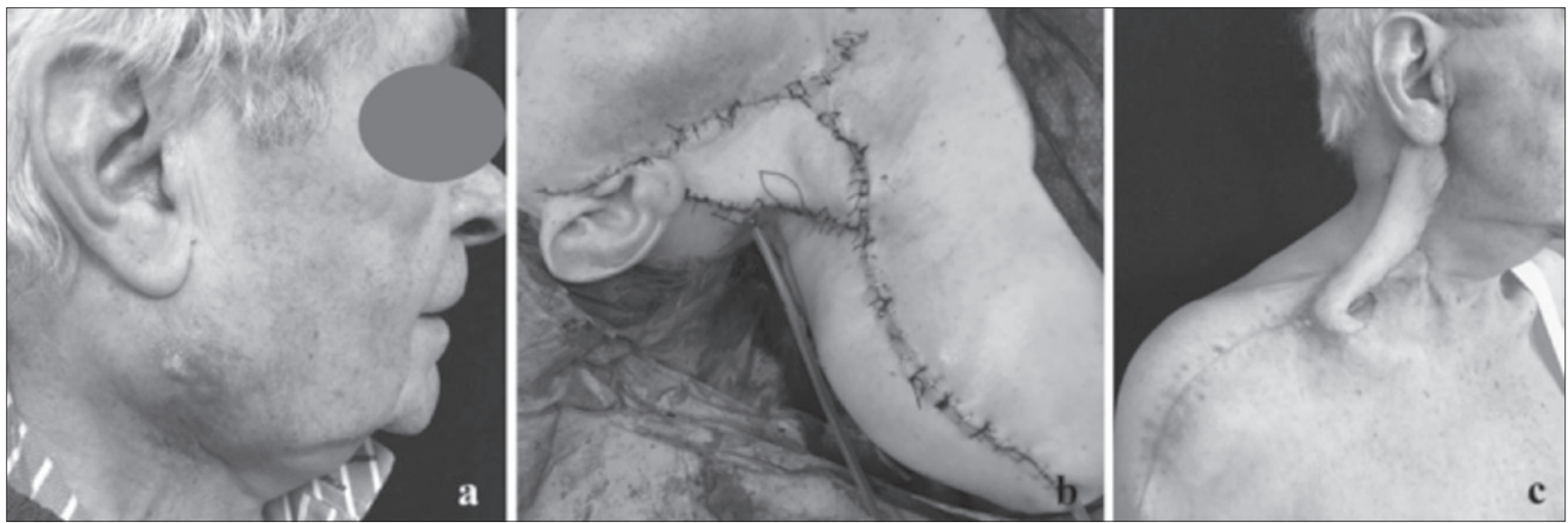

Fig. 3. Cervical skin reconstruction: preoperative appearance of a SCC lymph node metastasis involving cervical skin (a) and after tumour removal and SCAIF reconstruction (b), demonstrating optimal colour and texture of the flap (c).

Nonetheless, accurate preoperative assessment of flap feasibility is advisable. SCAIF is pedicled on the supraclavicular artery, a branch of the transverse cervical artery. The pencil Doppler probe is a very useful tool to locate the artery both preoperatively and intraoperatively ${ }^{910}$. However, in our experience it can sometimes be hard to draw the course of the artery preoperatively. If there is any doubt about the presence and location of the supraclavicular artery, angio-CT ${ }^{16}$ can be a valuable resource to aid in safe flap harvesting. This is especially true for patients who already underwent previous surgeries on the neck, as the transverse cervical artery is encountered during dissection of the lower portion of Robbins level IV ${ }^{17}$, where it can be damaged.

The second advantage of SCAIF is its high versatility. We used SCAIF for facial and cervical skin, oral cavity, oropharynx and hypopharynx, always with good results. Similar applications are described in the literature ${ }^{5-10 ~ 12-15}$. In particular, SCAIF seems to be very useful for hypopharyngeal reconstructions ${ }^{18}$ for several reasons: the flap can be harvested bilaterally, giving to the surgeon the possibility to choose the side with the most convincing pedicle; the site of reconstruction is very close, so that a shorter flap can be harvested, reducing possible complications to the distal portion; SCAIF can be harvested both in men and in women; SCAIF may also be used as a pharyngeal interposition flap to protect the suture of the neopharynx in a previously irradiated patient ${ }^{18}$, even if in our series this was never attempted. Tracheostomal defects reconstruction have also been described with good results ${ }^{18-20}$.

In addition, facial and cervical skin reconstructions are very satisfactory ${ }^{347}$. In our patients, colour and texture always showed a good match to the recipient site. SCAIF is a valid alternative even in cases of skin recurrence on previously irradiated fields or after previous surgeries, as skin transferred from the shoulder do not suffer from previous treatments. In fact, previous radiation therapy on the neck is not a contraindication to flap harvesting.

SCAIF is thin, pliable and hairless, providing a valid alternative for reconstruction of oral and oropharyngeal de-

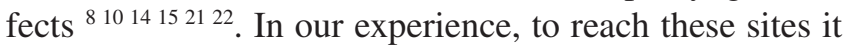
is necessary to harvest longer flaps with more potential complications.

A third advantage, but not less remarkable, is the reproducibility of SCAIF. Following the technique described by Kokot ${ }^{10}$, our results were consistent in all four centres, with a low complication rate. Such a small number of complications is reported in the literature ${ }^{2}$. Notably, in our series all complications to the recipient site occurred at the distal portion of the flap. We reported both simple tip desquamation and partial flap loss. When harvesting the flap, it is mandatory to carefully check for bleeding at the distal portion, and to eventually trim the flap back if there is any doubt ${ }^{10}$. In fact, the distal portion is the most delicate area, as it may suffer from reduced vascularisation, being the terminal portion of the angiosome ${ }^{4}$. For this reason, longer flaps are more prone to develop complications: 3 of the 4 recipient site complications in our series occurred when reconstructing the most distant sites. It is reported that most complications occur in flaps longer than $22 \mathrm{~cm}$, and to stop harvesting $5 \mathrm{~cm}$ beyond the point where the artery can be located with the Doppler ${ }^{10}$. Preoperative Doppler drawing of the artery and intraoperative Doppler check are crucial, especially if a long flap is needed. If the flap is used for reconstructing the floor of mouth, oropharynx or hypopharynx, even a simple distal tip desquamation may produce salivary infiltration, resulting in partial flap loss and consequent fistula: this even- 
tuality was faced in the two cases that needed revision surgery.

Eventual flap loss does not preclude the possibility of other reconstructive options, including free tissue transfer. We never observed recipient site infections. In fact, SCAIF has a relatively low incidence of surgical site infections, and even in the setting of a surgical site infection it usually remains viable. Clean-contaminated surgeries are associated with an increased risk of infection ${ }^{23}$.

Complications to the donor site are not frequent ${ }^{2}$, as the skin of the shoulder can be widely undermined to slide and cover the defect ${ }^{10}$. In our series we reported one intraoperative death, as well as some systemic complications. None of these complications were related to the choice of the flap, but rather to patient selection. In our series, SCAIF was used in most fragile patients: longer and more complicated procedures, as for example during free flap reconstruction, may have caused even worse outcomes.

To reconstruct cervical or facial skin defects, the flap can be tunnelled under the skin or simply rotated to cover the defect. It has to be noted that if the flap is simply rotated, it doesn't really match the definition of "island" flap ${ }^{24}$. However, harvesting technique and potential complications are exactly the same, and the flap still lives on its axial vascular pedicle. For this reason, these cases (marked in Table I) were still included in our report.

It is still under discussion if SCAIF can be an alternative to free tissue transfer in head and neck reconstruction. Results obtained with SCAIF and with free flaps have been compared in only a few papers ${ }^{1525}$. All found comparable or better results with SCAIF than with free flaps in terms of operative time, ICU stay, complications, hospitalisation and costs. Granzow ${ }^{1}$ and Welz ${ }^{15}$ refer that in their institutions, SCAIF has largely supplanted free flaps reconstruction techniques. Notwithstanding, these are all retrospective studies, with possible selection biases. A perspective multicentre randomised study comparing SCAIF and free flaps (in particular RFFF) is needed.

Recently, Pallua et al. modified the supraclavicular flap by introducing the anterior supraclavicular perforator flap, which is based on the anterior branch of the transverse cervical artery. This new flap is harvested in the deltopectoral fossa; it is thinner, more pliable and with a superior colour match to the face and neck skin ${ }^{26}$. It can even be pre-expanded to considerably increase its size ${ }^{27}$.

\section{Conclusions}

SCAIF is a reliable and versatile alternative for head and neck reconstructions. It is quick and easy to harvest and is best suited to the most fragile patients. Its easy repro- ducibility is another advantage that hasn't been assessed previously. We began using the SCAIF in four Head and Neck Surgery Departments, with excellent and consistent results in all four centres. The very short learning curve, high versatility and possibility to use it as an alternative to free flap in selected cases should encourage head and neck surgeons to start using the SCAIF.

\section{Conflict of interest statement}

None declared.

\section{References}

1 Granzow JW, Suliman A, Roostaeian J, et al. Supraclavicular artery island flap (SCAIF) vs free fasciocutaneous flaps for head and neck reconstruction. Otolaryngol Head Neck Surg 2013;148:941-8.

2 Giordano L, Di Santo D, Occhini A, et al. Supraclavicular Artery Island Flap (SCAIF): a rising opportunity for head and neck reconstruction. Eur Arch Otorhinolaringol 2016;273:4403-12.

3 Pallua N, Machens H, Rennekampff O, et al. The fasciocutaneous supraclavicular artery island flap for releasing postburn mentosternal contractures. Plast Reconstr Surg 1997;99:1878-84.

4 Pallua N, Noah EM. The tunneled supraclavicular island flap: an optimized technique for head and neck reconstruction. Plast Reconstr Surg 2000;105:842-51.

5 Chiu ES, Liu PH, Friedlander PL. Supraclavicular artery island flap for head and neck oncologic reconstruction: indications, complications, and outcomes. Plast Reconstr Surg 2009;124:115-23.

6 Kim RJT, Izzard ME, Patel RS. Supraclavicular artery island flap for reconstructing defects in head and neck region. Curr Opin Otolaryngol Head Neck Surg 2011;19:248-50.

7 Sandu K, Monnier P, Pasche P. Supraclavicular flap in head and neck reconstruction: experience in 50 consecutive patients. Eur Arch Otorhinolaryngol 2012;269:1261-7.

8 Alves HR, Ishida LC, Ishida LH, et al. A clinical experience of the supraclavicular flap used to reconstruct head and neck defects in late-stage cancer patients. J Plast Reconstr Aesthet Surg 2012;65:1350-6.

9 Granzow JW, Suliman A, Roostaeian J, et al. The supraclavicular artery island flap (SCAIF) for head and neck reconstruction: surgical technique and refinements. Otolaryngol Head Neck Surg 2013;148:933-40.

10 Kokot N, Mazhar K, Reder LS, et al. The supraclavicular artery island flap in head and neck reconstruction. Applications and limitations. JAMA Otolaryngol Head Neck Surg 2013;139:1247-55.

11 Hanasono $\mathrm{MH}$, Matros E, Disa JJ. Important aspects of head and neck reconstruction. Plast Reconstr Surg 2014;134:968-80. 
12 Sands TT, Martin JB, Simms E, et al. Supraclavicular artery island flap innervation: anatomical studies and clinical implications. J Plast Reconstr Aesthet Surg 2012;65:68-71.

13 Giordano L, Bondi S, Toma S, et al. Versatility of the supraclavicular pedicle flap in head and neck reconstruction. Acta Otorhinolaryngol Ital 2014;34:394-8.

14 Anand AG, Tran EJ, Hasney CP, et al. Oropharyngeal reconstruction using the supraclavicular artery island flap: a new flap alternative. Plast Reconstr Surg 2012;129:438-41.

15 Welz C, Canis M, Schwenk-Zieger S, et al. Oral cancer reconstruction using the supraclavicular artery island flap: comparison to free radial forearm flap. J Oral Maxillofac Surg 2017;75:2261-9.

16 Adams AS, Wright MJ, Johnston S, et al. The use of multislice CT angiography preoperative study for supraclavicular artery island flap harvesting. Ann Plas Surg 2012;69:312-5.

17 Robbins KT, Shaha AR, Medina JE, et al. Consensus statement on the classification and terminology of neck dissection. Arch Otolaryngol Head Neck Surg 2008;134:536-8.

18 Emerick KS, Herr MA, Deschler DG. Supraclavicular flap reconstruction following total laryngectomy. Laryngoscope 2014; 124:1777-82.

19 Pallua N, Wolter TP. Defect classification and reconstruction algorithm for patients with tracheostomy using the tunneled supraclavicular artery island flap. Langenbecks Arch Surg 2010;395:1115-9.
20 Chu MW, Levy JM, Friedlander PL, et al. Tracheostoma reconstruction with the supraclavicular artery island flap. Ann Plast Surg 2015;74:677-9.

21 Chen WL, Zhang DM, Yang ZH, et al. Extended supraclavicular fasciocutaneous island flap based on the transverse cervical artery for head and neck reconstruction after cancer ablation. J Oral Maxillofac Surg 2010;68:2422-30.

$22 \mathrm{Wu}$ H, Chen WL, Yang ZH. Functional reconstruction with an extended supraclavicular fasciocutaneous island flap following ablation of advanced oropharyngeal cancer. J Craniofac Surg 2012;23:1668-71.

23 Goyal N, Emerick KS, Deschler DG, et al. Risk factors for surgical site infection after supraclavicular flap reconstruction in patients undergoing major head and neck surgery. Head Neck 2016;38:1615-20.

24 Kimyai-Asadi A, Goldberg LH. Island pedicle flap. Dermatol Clin 2005;23:113-27.

25 Kozin ED, Sethi RK, Herr M, et al. Comparison of perioperative outcomes between the supraclavicular artery island flap and fasciocutaneous free flap. Otolaryngol Head Neck Surg 2016;154:66-72.

26 Pallua N, Wolter TP. Moving forwards: the anterior supraclavicular artery perforator ( $a-S A P)$ flap: a new pedicled or free perforator flap based on the anterior supraclavicular vessels. J Plast Recontr Aesthet Surg 2013;66:489-96.

27 Pallua N, Kim BS. Pre-expanded supraclavicular artery perforator flap. Clin Plast Surg 2017;44:49-63.

Received: September 6, 2017 - Accepted: November 22, 2017

Address for correspondence: Davide Di Santo, Otolaryngology Service, Head and Neck Department, San Raffaele Hospital, Vita-Salute University, via Olgettina 60, 20123 Milan, Italy. Tel. +39 0226432172. Fax +3902 26433508. E-mail: disanto.davide@hsr.it 